STRUCTURAL SCIENCE CRYSTAL ENGINEERING MATERIALS

ISSN 2052-5206

\section{Imperfections in crystalline solids. By Wei Cai and William D. Nix. MRS-Cambridge Materials Fundamentals. Cambridge University Press, 2016. Paperback Pp. 532. Price GBP 44.99. ISBN 1107123135}

\author{
Denis Gratias*
}

Received 3 October 2016

Accepted 22 May 2017

Keywords: book review; imperfections; crystalline solids

Supporting information: this article has supporting information at journals.iucr.org/b

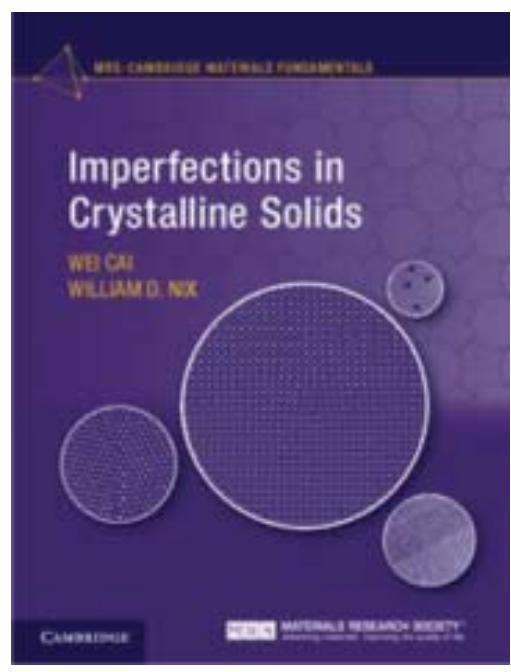

IRCP Chimie-ParisTech, 11 rue Pierre et Marie Curie, Paris, 75005, France.

*Correspondence e-mail: denis.gratias@chimie-paristech.fr

This book is a very good textbook of more than 500 pages that bridges the gap between Introduction to Dislocations by Hull \& Bacon (2011), and the famous Theory of Dislocations by Hirth \& Lothe (1968). It is based on the lecture notes of one the authors (WDN), who originally taught in the Materials Science and Engineering Department of Stanford University. It is mainly aimed at senior undergraduate and junior graduate students and is clearly one of the best set of lectures for a basic understanding of classical defects in crystals. The book consists of 14 chapters grouped in four main parts:

Theoretical background (elasticity, statistical thermodynamics);

Point defects (mechanics, thermodynamics, equilibria and kinetics) in metals, covariant and simple ionic structures;

Dislocations (geometry, mechanics, interactions, partial dislocations and core structures) mostly in metals;

Grain boundaries (geometry and mechanics) essentially in metals.

One of the most obvious qualities of this book is its internal completeness in all classical aspects of studying defects in crystals. Every single equation, from geometry to mechanical properties, is clearly derived with numerous intermediate calculations that quickly allow the important results to be (re)established. Each chapter is illustrated with many figures and experimental examples and with a remarkably large number of highly pertinent exercises that are often very interesting recent extensions from the main body of the book. All together, this book is of equal interest for students and professionals. The only possible restriction is that it is focused essentially on metals and simple ordered alloys, i.e. to strictly crystalline structures; it thus describes well established results on well-known structures. But the book does not mention, even in a single sentence, the existence of the plentiful number of long-range ordered quasicrystals and incommensurate structures discovered in the last thirty years in many alloys and that belong to the new extended definition of a crystal (IUCr, 1992, p. 928). These structures bring new kinds of defects (phasons, phason walls, metadislocations, etc) that would certainly deserve being included and discussed in a textbook of the XXI century. Let us hope to find them in the next edition of the book... .

\section{References}

Hirth, J. P. \& Lothe, J. (1968). Theory of Dislocations. New York: McGraw-Hill.

Hull, D. \& Bacon, D. J. (2011). Introduction to Dislocations, 5th Ed. Oxford: ButterworthHeinemann.

IUCr (1992). Acta Cryst. A48, 922-946. 